\title{
The effect of cuts in medical assistance on low- income dental school patients seeking periodontal treatment
}

\begin{abstract}
Objectives: Scaling and root-planing is basic treatment for periodontal disease. Historically, large numbers of patients treated by University of Pittsburgh dental students pay for services through government-sponsored public funding programs. In Sept. 2011, Pennsylvania's Medical Assistance program largely eliminated any payments for routine dental procedures when the state governor then in office declined to opt-into Medicaid expansion. The objective of this research was to determine the extent of dental patient care at the University impacted by the decision.
\end{abstract}

Methods: Retrospective analysis of the Electronic Health Record database regarding patients seeking scaling and root-planing while eligible for dental procedure reimbursement under federal or state public financing programs. Those numbers of patients for the period Sept. 2008 through Sept. 2011, when procedure reimbursement was offered under Pennsylvania state Medicaid, are compared with numbers seeking scaling and root-planing during the subsequent three-year state discontinuation of Medical Assistance.

Results: From Sept. 2008 (beginning of the database) to September 1, 2011, during the period when Pennsylvania Medical Assistance was operating at full strength to reimburse periodontal procedures, 993 Medical Assistance periodontal patients were seen, compared to 2454 periodontal patients in the general dental school population. After the cuts in Medical Assistance, 560 Medical Assistance periodontal patients were seen in the period until Sept. 1, 2014, compared to 1960 periodontal patients in the general dental student patient pool. Reduction in the number of patients without procedure reimbursement under Medicaid was more significant $(\mathrm{p}<.001)$ than the reduction in patient numbers overall.

Conclusion: Basic periodontal treatment at this dental school was affected significantly $(\mathrm{p} \leq 0.01)$ when the former state government in Pennsylvania declined to opt-into state Medicaid expansion as provided for by the 2010 Affordable Care Act.
Volume 4 Issue I - 2016

\author{
Pouran Famili,' Ahmad Kamal' \\ 'Professor, Department of Periodontics and Preventive \\ Dentistry, University of Pittsburgh, USA \\ ${ }^{2}$ Department of Periodontics and Preventive Dentistry, \\ University of Pittsburgh, USA
}

Correspondence: Pouran Famili, Professor, Department of Periodontics and Preventive Dentistry, University of Pittsburgh, USA, Tel +(4I 2) 648-9997, Fax (4I 2) 648-8594, Email rav3@pitt.edu

Received: November 25, 2015 | Published: January 28, 2016

Keywords: periodontal, root-planing, retrospective, scaling

\section{Introduction}

About one out of three persons living in the United States has periodontal disease. ${ }^{1}$ Periodontal disease is more severe among African Americans, Hispanics, and men. ${ }^{1}$ Periodontal health has an established clinical relationship with chronic systemic conditions like diabetes, cardiovascular disease, and obesity, and periodontal treatment has been shown to improve dental health as well as general health. Basic periodontal treatment starts with home care and scaling and root planing, the treatment of choice for patients with mild-tomoderate periodontitis with clinical attachment loss equal to or greater than $4 \mathrm{~mm} .^{2}$

The 2010 Affordable Care Act represents the most significant overhaul of the U.S. healthcare system since 1965, when the New Deal Social Security Act was amended by the introduction of Medicare and Medicaid. Generally understood, Medicare is hospital and general medical insurance for senior citizens paid for by a Federal employment tax over the working life of the retiree. The states offer health-care reimbursement programs for the poor partially funded by the federal government but managed and co-funded individually by the states, in an attempt to provide some social safety net for millions of uninsured poor Americans. When the U.S. Supreme Court ruled in 2012 that the Medicaid expansion by the states required under the Affordable Care Act was unconstitutional, at least 21 states-including Pennsylvania-declared intent to opt out of that mandate. Some, like Pennsylvania, presented replacement public financing schemes for the poor and uninsured that were never accepted as alternatives to the federal law and thus never implemented. At the University of Pittsburgh dental school, where many of the patient procedures are paid for by Pennsylvania State Medical Assistance, the faculty was interested in assessing the effect of cuts in state public financing on patient care.

\section{Methodology}

This was a retrospective study looking at the number of patients seeking basic periodontal treatment (scaling and root-planing) at the University of Pittsburgh School of Dental Medicine while they were eligible for dental procedure reimbursement under federal Medicare or Commonwealth of Pennsylvania Medical Assistance, and during the subsequent three-year state government discontinuation of Medical 
Assistance coverage for the initial phase of periodontal treatment We also looked at patients without Medicare or Medical Assistance coverage who sought similar periodontal treatment during the same period at the University of Pittsburgh School of Dental Medicine. This research was an analysis of existing paperless Electronic Health Record data collected and stored via axiUm ${ }^{\mathrm{TM}}$ dental software [Exan Group, Las Vegas] at the University of Pittsburgh dental school, from September 2008 to September 2014. Pearson chi-squared analysis was performed using Stata ${ }^{\circledR}$.

\section{Results}

During the three-year period before 09-01-2011, 993 patients with Medicare or Medicaid dental procedure reimbursement sought initialphase periodontal treatment at the School of Dental Medicine. After the state-mandated change on 09-01-2011, the number of patients fell to 560 (Table 1). By comparison, patients without Medicare or Medicaid dental procedure reimbursement coming to the dental school for initial-phase periodontal treatment totaled 2454 in the three-year period before 09-01-2011, that number falling to 1960 after 09-012011. There was a general reduction in the number of people seeking initial-phase periodontal treatment at the University of Pittsburgh School of Dental Medicine, but the reduction in numbers of people who no longer had dental procedure reimbursement by Medicare or Medicaid was statistically significant $(\mathrm{p}<.001)$.

Before the state change in Medical Assistance reimbursements, 28.8 percent of patients receiving initial-phase periodontal treatment were eligible for coverage for that treatment by Medicare or Medicaid; after the state change, only 22.2 percent of similar patients were eligible for coverage for that treatment by Medicare or Medicaid. This difference is statistically significant $(\mathrm{p}<0.01$ ). This shows the proportion of individuals eligible for dental procedure reimbursement by Medicare or Medicaid dropped significantly after the state government changed Medicaid-reimbursement guidelines (Table 2).

Table I SRP (scaling and root-planing) data four teeth per quad [ICD9-D434I] 09-0I-2008 through 09-0I-20I4

\begin{tabular}{|c|c|c|c|c|c|c|}
\hline & $\begin{array}{l}\text { Medicare Pt. } \\
\text { Before } 9 / 1 / 1 \mathrm{I}\end{array}$ & $\begin{array}{l}\text { Medicare Pt. } \\
\text { After } 9 / 1 / 1 / 1\end{array}$ & $\begin{array}{l}\text { Patients Without } \\
\text { Medicare Before } \\
9 / 1 / 1 / \text { I }\end{array}$ & $\begin{array}{l}\text { Patients Without } \\
\text { Medicare After } \\
9 / 1 / 201 \text { I }\end{array}$ & $\begin{array}{l}\text { Total Pt. } \\
\text { Before } 9 / \mathrm{I} / \mathrm{I}\end{array}$ & $\begin{array}{l}\text { Total Pt. } \\
\text { After } \\
9 / 1 / 11\end{array}$ \\
\hline \multirow[t]{2}{*}{ Years } & 993 & 560 & 2454 & 1960 & 3447 & 2520 \\
\hline & 3 & 3 & 3 & 3 & 3 & 3 \\
\hline Patients Per Year & 331 & 186.67 & 818 & 653.3 & 1149 & 840 \\
\hline \% Decrease in Patients & 43.604229 & & 20.134474 & & 26.892950 & \\
\hline
\end{tabular}

Table 2 Pearsons chi squared analysis of the before/after data

\begin{tabular}{llll}
\hline & Before change & After change & Total \\
\hline \multirow{4}{*}{ Medicaid } & 993 & 560 & 1,553 \\
& 63.94 & 36.06 & 100.00 \\
& 29.81 & 22.22 & 26.03 \\
No-Medicaid & 5,454 & 1,960 & 4,414 \\
& 71.19 & 44.40 & 100.00 \\
& 3,447 & 77.78 & 73.97 \\
Total & 57.77 & 4,520 & 5,967 \\
& 100.00 & 100.00 & 100.00 \\
\hline
\end{tabular}

Before the change, $28.8 \%$ of patients were Medicaid patients. After the change, $22.2 \%$ of patients were Medicaid patients. This difference is statistically significant $(\mathrm{p}<0.0 \mathrm{I})$. The proportion of Medicaid patients treated at our dental school significantly dropped after the state policy changes were made. Pearson chi $2(I)=32.7916, p=0.000$

\section{Discussion}

The dental-medical literature shows that individuals with lower socioeconomic status have a greater chance of developing periodontal disease. ${ }^{3}$ Research has also shown the higher the educational level, the lower the severity of periodontal disease. ${ }^{4}$ Our study showed that when dental procedure reimbursements were cut by the Pennsylvania state government in September 2011, individuals relying on state dental procedure reimbursement coverage sought less basic periodontal treatment. Within three years this reduction in provision of service (and treatment) was statistically significant $(\mathrm{p} \leq 0.01)$. Although the number of individuals seeking basic periodontal treatment fell overall, the reduction in number of individuals formerly covered by Medicare or Medicaid but now without Medicare or Medicaid was more significant $(\mathrm{p} \leq 0.01)$.

The first step of periodontal treatment is scaling and root-planing, complemented by strong home care and improved oral hygiene. Careful basic periodontal treatment can prevent subsequent more expensive dental treatment like periodontal surgery. Our experience is that the population who seeks dental treatment at the dental school is usually individuals who are unable or unwilling to seek dental treatment in a private dental practice. Without government-supported and-subsidized dental procedure reimbursement coverage, individuals in this set may not seek any dental treatment. The damaging effects on individual oral and systemic health or society generally are not exaggerated.

\section{Conclusion}

This research documented that cuts in government-supported dental treatment-reimbursement schedules (Medicaid) for basic periodontal treatment (scaling and root-planing) by the Pennsylvania state government in September 2011 bore significant effects $(p \leq 0.01)$ on patients seeking such basic periodontal treatment at the University of Pittsburgh School of Dental Medicine. 


\section{Funding}

None.

\section{Acknowledgements}

None.

\section{Conflicts of interest}

Authors declare that there is no conflict of interest.

\section{References}

1. Borrell LN, Talih M. Examining periodontal disease disparities among U.S. adults 20 years of age and older: NHANES III (1988-1994) and NHANES 1999-2004. Public Health Reports. 2012;127(5):497-506.
2. Lindhe J, Westfelt E, Nyman S,et al. Long-term effect of surgical/ non-surgical treatment of periodontal disease. $J$ of Clin Periodontol. 1984;11(7):448-458

3. Third National Health and Nutrition Examination Survey 1988-94. Hyattsville, MD: Centers for Disease Control 1997. 1998; Public Use Data File No. 7-0627.

4. Markkanen H, Rajala M, Knuuttila M, et al. Alveolar bone loss in relation to periodontal treatment need, socioeconomic status and dental health. $J$ Periodontol. 1981;52(2):99-103. 